\title{
Fish, a Mediterranean source of $n-3$ PUFA: benefits do not justify limiting consumption
}

\author{
Angel Gil ${ }^{1 *}$ and Fernando Gil ${ }^{2}$ \\ ${ }^{1}$ Department of Biochemistry and Molecular Biology II, Institute of Nutrition and Food Technology "Jose Mataix", \\ Biomedical Research Centre, University of Granada, Avenida del Conocimiento s/n, 18100 Armilla, Granada, Spain \\ ${ }^{2}$ Department of Legal Medicine and Toxicology, School of Medicine, University of Granada, Granada, Spain
}

(Submitted 17 June 2014 - Final revision received 4 September 2014 - Accepted 22 October 2014)

\begin{abstract}
Fish is an important source of energy, high-quality proteins, fat, vitamins and minerals. Within lipids, $n$-3 long-chain PUFA ( $n$ - 3 LC PUFA), mainly EPA and DHA, play an important role in health promotion and disease prevention. In contrast to the potential health benefits of dietary fish intake, certain chemical pollutants, namely heavy metals and some organic compounds, contained in seafood have emerged as an issue of concern, particularly for frequent fish consumers and sensitive groups of populations. The present review summarises the health benefits and risks of fish consumption. $n$-3 LC-PUFA are key compounds of cell membranes and play an important role in human health from conception through every stage of human development, maturation and ageing. DHA has a major role in the development of brain and retina during fetal development and the first 2 years of life and positively influences neurodevelopment, mainly visual acuity and cognitive functions. $n$-3 LC-PUFA are also effective in preventing cardiovascular events (mainly stroke and acute myocardial infarction) especially in persons with high cardiovascular risk. By contrast, there is convincing evidence of adverse neurological/neurodevelopmental outcomes in infants and young children associated with methylmercury exposure during fetal development due to maternal fish consumption during pregnancy. Dioxins and polychlorinated biphenyls present in contaminated fish may also develop a risk for both infants and adults. However, for major health outcomes among adults, the vast majority of epidemiological studies have proven that the benefits of fish intake exceed the potential risks with the exception of a few selected species in sensitive populations.
\end{abstract}

\section{Key words: Dioxins: Fish Health risks: Fish benefits: Methylmercury: Omega-3 fatty acids: Polychlorinated biphenyls}

Fish has been acknowledged as an integral component of a well-balanced diet, providing a healthy source of energy, high-quality proteins, vitamins ( $\mathrm{D}, \mathrm{A}, \mathrm{E}$ and $\mathrm{B}_{12}$ ), essential metals (Se, Mn and $\mathrm{Cu}$ ) and especially $n-3$ long-chain PUFA (n-3 LC-PUFA), mainly EPA and DHA, whose pleiotropic effects in health promotion and disease prevention are increasingly known.

Hence, $n$-3 LC-PUFA play a vital role in human health from conception through every stage of human development, maturation and ageing ${ }^{(1-5)}$. Reported health benefits of these fatty acids include lowering the risk of $\mathrm{CHD}^{(6-9)}$ and contributing to normal neurodevelopment in children ${ }^{(10-12)}$.

In contrast to the potential health benefits of dietary fish intake, certain chemical pollutants (e.g. heavy metals, polycyclic aromatic hydrocarbons, polychlorinated biphenyls (PCB), polybrominated diphenyl ethers, dioxins, furans and chlorinated pesticides) contained in seafood have emerged as an issue of concern, particularly for frequent fish consumers and sensitive groups of populations ${ }^{(6,13-17)}$. These chemicals have adverse effects on nervous system function, modulate

\footnotetext{
Abbreviations: LC, long chain; PCB, polychlorinated biphenyls; PCDD, polychlorinated dibenzo- $p$-dioxins; PCDF, polychlorinated dibenzofurans.

*Corresponding author: A. Gil, fax +34958 819132, email agil@ugr.es

Publication of these papers was supported by unrestricted educational grants from Federación Española de Sociedades de Nutrición, Alimentación y Dietética (FESNAD), International Nut and Dried Fruit Council (INC), International Union of Nutritional Sciences (IUNS), Fundación Iberoamericana de Nutrición (FINUT), Centro de Investigación Biomédica en Red de la Fisiopatología de la Obesidad y Nutrición (CIBERobn) and Centro Interuniversitario di Ricerca sulle Culture Alimentari Mediterranee (Ciiscam). The papers included in this supplement were invited by the Guest Editors and have undergone the standard journal formal review process. They may be cited. The Guest Editors declare that Salas-Salvadó is a nonpaid member of the World Forum for Nutrition Research and Dissemination of the International Nut and Dried Fruit Council. Angel Gil is President of the Fundación Iberomericana de Nutrición, which is a non-paid honorary position. Lluis Serra-Majem is the President of the Scientific Committee of the Mediterranean Diet Foundation and Scientific Director of the CIISCAM (Centro Interuniversitario di Ricerca sulle Culture Alimentari Mediterranee), Universita La Sapienza di Roma which are both non-paid, honorary positions. Goretti Guasch is the Executive Director and Member of the Executive Committee of the International Nut and Dried Fruit Council, which is a paid position. Mònica Bulló declares no conflict of interest.
} 
the immune system and are associated with elevation in the risk of CVD. Therefore, the question of benefits and risk from fish consumption is very complex and relevant ${ }^{(6,18)}$

The Codex Committee on Food Additives and Contaminants requested the Codex Alimentarius Commission to seek scientific advice from the FAO of the UN and the WHO on the health risks and health benefits of fish consumption, particularly the health risks associated with the contaminants methylmercury and dioxins (including polychlorinated dibenzo- $p$-dioxins (PCDD) and polychlorinated dibenzofurans (PCDF) as well as dioxin-like PCB) that may be present in fish. That request was based on the growing public concern in recent years regarding the presence of chemical contaminants in fish $v$. the multiple nutritional benefits of including fish in the diet have become increasingly scientifically documented and proven. Indeed, the FAO and WHO held an Expert Consultation on the Risks and Benefits of Fish Consumption in $2010^{(6)}$. This review should be considered as a master document to assess the risk-benefit for specific end points, including those for sensitive groups of population. In fact, the Expert Consultation drew a number of conclusions regarding the health benefits and health risks associated with fish consumption and recommended a series of steps that Member States should take to better assess and manage the risks and benefits of fish consumption and more effectively communicate these risks and benefits to their citizens.

The present review summarises the work on the benefits and risks of fish consumption presented during the World Nutrition Research Conference on Mediterranean Foods in Heath and Disease, held in Reus, Spain in May 2013, as a Satellite Conference of the 20th International Congress of Nutrition.

\section{Nutrient composition of fish and seafood products}

Fish and other seafood products, namely molluscs, crustaceans and echinoderms, consumed directly or processed provide a huge variety of products of interest for nutritional benefits in human. The detailed composition of finfish, crustacean, mollusc and echinoderm species can be found in a selected number of international databases (United States Department of Agriculture National Nutrient Database for Standard Reference Nutrient Data Laboratory (NDL)/Food and Nutrition Information Center (FNIC) Food Composition Database, http://ndb.nal.usda.gov; SELFNutritionData, http:// nutritiondata.self.com; International Network of Food Data Systems Standards and Guidelines, http://www.fao.org/ infoods/infoods/standards-guidelines/en/as well as in some national databases, e.g. Base española de datos de composición de alimentos, http://www.bedca.net/

Depending on the species, fish has a water content ranging 60-80\% weight and the marine invertebrates 53-96\%. The $\mathrm{N}$ fraction is composed of proteins (12-20\%) and of nonprotein $\mathrm{N}$ compounds (1-2\%). Seafood proteins have a high digestibility and biological value because muscles mainly constitute sarcoplasmic (myoalbumin, globulins and enzymes) and myofibrillar proteins (actin, myosin and tropomyosin) with a very low content of connective proteins (collagen ranging 3-10\%, compared with $17 \%$ of mammals). All essential amino acids are present in fish protein in adequate amounts compared with milk, eggs and meat. Free amino acids, namely histidine and taurine, some peptides, such as anserine and carnosine, as well as other non-protein compounds, such as free nucleotides and creatine, are also present in comparatively high amounts ${ }^{(3,19)}$.

Lipids are important nutrients for fish. Depending on its lipid content, fish is classified into lean fish $(<2.5 \%$ fat, mainly Gadidae and Pleuronectidae, e.g. cod, haddock, saithe and sole), medium fatty fish (2.5-6\% fat, mainly Merlucciidae and Phycidae, e.g. hake, sea bass and ocean perch) and fatty fish (>6-25\% fat, mainly Cupleidae, Engraulidae, Scombridae and Salmonidae, e.g. anchovy, herring, sardine, mackerel, tunas, bonitos and salmon). The quantitative and qualitative lipid contents vary according to the species, age, sex, period of the year, etc. n-3 LC-PUFA are key compounds abundant in sea fish, ranging from about $0.2 \%$ weight in lean fish to about 3\% weight in fat fish. Crustaceans, shellfish and cephalopods are lean species with lipid content ranging $0 \cdot 9-2 \cdot 2 \%{ }^{(3,19)}$.

Fish have on average $35 \mathrm{mg}$ cholesterol/100 $\mathrm{g}$ and contribute little to the dietary cholesterol intake. However, most of crustaceans, e.g. shrimps and prawns, show high contents of cholesterol (about 100-150 mg/100 g). Even higher levels are found in cephalopods $(>200 \mathrm{mg} / 100 \mathrm{~g}$ ) and the richest content is found in fish eggs and derived by-products such as caviar (about $500 \mathrm{mg} / 100 \mathrm{~g})^{(3,19)}$.

The carbohydrate content of fish and other seafood products is usually lower than $0 \cdot 5 \%^{(19)}$.

The amount of vitamins and minerals is species-specific and varies according to the diet and season of the year. Fish is considered a good source of Ca (about $10-100 \mathrm{mg} / 100 \mathrm{~g}$ ), $\mathrm{Mg}(10-170 \mathrm{mg} / 100 \mathrm{~g})$ and $\mathrm{P}(200-300 \mathrm{mg} / 100 \mathrm{~g})$, as well as F $(300-400 \mu \mathrm{g} / 100 \mathrm{~g}), \quad \mathrm{I} \quad(10-300 \mu \mathrm{g} / 100 \mathrm{~g})$, Se $(35-45 \mu \mathrm{g} /$ $100 \mathrm{~g}), \mathrm{Fe}(0.3-2 \cdot 8 \mathrm{mg} / 100 \mathrm{~g}), \mathrm{Zn}(0.3-1.3 \mathrm{mg} / 100 \mathrm{~g})$ and $\mathrm{Cu}$ $(0 \cdot 1-0 \cdot 2 \mathrm{mg} / 100 \mathrm{~g})$. However, fish is a poor source of $\mathrm{Na}$ $(20-140 \mathrm{mg} / 100 \mathrm{~g})$ but rich in $\mathrm{K}(200-400 \mathrm{mg} / 100 \mathrm{~g})$. Seafood products are one of the few natural sources of $\mathrm{I}$ and $\mathrm{Se}^{(3,19)}$. The highest Se levels are usually present in tuna, swordfish and scad ${ }^{(16)}$. Mussels, scad and sardines are the fresh species with the highest $\mathrm{Zn}$ levels. Molluscs and crustaceans are the major contributors of $\mathrm{Cu}$ and $\mathrm{Fe}$; their remarkable concentration of $\mathrm{Cu}$ could be accounted for the presence of haemocyanin, a Cu-containing respiratory protein found in the blood of those species ${ }^{(16,20)}$.

Fish is rich in vitamins, namely thiamin (vitamin $\mathrm{B}_{1}$ ) $(40-210 \mu \mathrm{g} / 100 \mathrm{~g})$, riboflavin (vitamin $\left.\mathrm{B}_{2}\right)(50-360 \mu \mathrm{g} / 100 \mathrm{~g})$, niacin (vitamin $\left.\mathrm{B}_{3}\right)(2-10 \mathrm{mg} / 100 \mathrm{~g})$, pyridoxine $(200-980 \mu \mathrm{g} /$ $100 \mathrm{~g}$ ) and specially cobalamin (vitamin $\left.\mathrm{B}_{12}\right)(1-9 \mu \mathrm{g} / 100 \mathrm{~g})$. Clupeidae and Engraulidae exhibit the highest content of vitamin $\mathrm{B}_{12}$. Liposoluble vitamins, mainly vitamins $\mathrm{A}$ and $\mathrm{D}$, are mostly accumulated in the liver, although some species also exhibit a high content in the muscle mass. It is well known that high content of vitamins $\mathrm{A}$ and $\mathrm{D}$ is present in the liver of codfish species. Vitamin A in fish fillet ranges 3-180 mcg (micrograms)/100 g. The vitamin D content of fish may vary enormously and it is not well correlated with the fat content, values range $3-20 \mu \mathrm{g} / 100 \mathrm{~g}^{(3,19,21)}$. 


\section{Health outcomes related to fish and other seafood consumption}

The epidemiological evidence to support the consumption of seafood is mainly derived from cohort studies. However, it is difficult to identify which nutrient is important due to the presence of other covariants in the $\operatorname{diet}^{(21)}$.

Moderate-to-high intake of fish has been associated with a decrease in the prevalence of chronic diseases associated with obesity, namely CVD, diabetes and some cancers ${ }^{(3,21)}$. Although $n$-3 LC-PUFA, derived mainly from fatty fish, have been the most important focus of research related to benefits of fish consumption and because of their relevant benefits will be considered separately in the present report, protein, some non-protein $\mathrm{N}$ compounds, namely taurine and choline, some minerals, particularly $\mathrm{Se}$, and vitamins $\mathrm{B}_{12}$ and $\mathrm{D}$ have been reported to be associated in protection against CHD. Seafood consumption is associated with reduced markers of inflammation ${ }^{(22)}$, which can explain, at least in part, its effect of protection against CVD and diabetes. It is also associated to reduced blood pressure and less vascular damage ${ }^{(23)}$. Meta-analyses of cohort studies also suggest a strong protective effect of stroke ${ }^{(24,25)}$. This effect cannot be exclusively attributed to EPA and DHA, but also to other seafood components. Thus, taurine in experimental animals have positive effects on the cardiovascular system and diabetes. In addition, it has been associated with a number of health effects such as better fat digestion and visual acuity improvement in infants ${ }^{(26)}$. Vitamin $B_{12}$ can also be important in relation to both CVD and stroke through reduction of plasma homocysteine $^{(27)}$. Mineral elements are among the most important nutrients provided by fish because they participate in many biological processes. In fact, seafood consumption may contribute to the reduction in the prevalence of mineral inadequacies and as a consequence seafood consumption could be promoted ${ }^{(20)}$. $\mathrm{Zn}$ is a cofactor to more than 300 enzymes involved in important functions such as RNA and DNA metabolism and plays a major role in the stabilisation of the structure of a large number of proteins, including signalling enzymes at all levels of cellular signal transduction ${ }^{(28)}$. Through its ability to change oxidation state, $\mathrm{Cu}$ is a wellestablished essential element that is required as a catalytic cofactor in numerous critical enzyme reactions ${ }^{(29)}$. Se is a critical component of numerous selenoproteins in humans, some of which are important antioxidant systems (e.g. glutathione peroxidase) that actively protect against damage from free radicals and reactive oxygen species, which in turn could protect against cancer or $\mathrm{CVD}^{(30,31)}$. Fish intervention studies, e.g. SEAFOOD Plus and AQUAMAX, funded by the European Union, have focused on biomarkers of effect. Indeed, the intake of 300-450 g/week of both cod and salmon improves the Se status and contributes to the reduction of inflammatory and cardiovascular biomarkers and lead to some benefit in weight control and blood pressure ${ }^{(32)}$. Similarly, in pregnant women, the weekly intake of two portions of salmon is associated to a better status of Se in mothers and their newborns, as well as to a higher activity of glutathione peroxidase ${ }^{(33)}$. Several studies also showed that Se may protect against the toxic effects of $\mathrm{Hg}$, particularly organic methylmercury ${ }^{(34,35)}$. Accordingly, the Hg:Se ratio could be a useful tool to better assess the risk associated with fish intake, especially in predatory species such as tuna ${ }^{(16,36)}$.

Large cohort studies show that fish intake is not associated with either increase or decreases in the risk of cancer overall. However, there is significant evidence of protection for colorectal cancer ${ }^{(37)}$ and some evidence in relation to prostate cancer ${ }^{(38)}$. Not only $n$-3 LC-PUFA but also vitamin D and Se can have a role in this protective effect ${ }^{(21)}$.

\section{Health benefits of fish consumption related to $n$-3 long-chain PUFA}

$n$-3 LC-PUFA are conditionally essential nutrients for adequate growth, development and function in humans. The effects

Table 1. Levels of evidence of effects of fish and $n-3$ long-chain (LC) PUFA consumption on disease prevention

\begin{tabular}{|c|c|}
\hline Diseases & Levels of evidence \\
\hline Asthma & A possible benefit (with adequate dose) in children but with no evidence of benefit in adults \\
\hline \multicolumn{2}{|r|}{ P } \\
\hline BC & $\begin{array}{l}\text { There is limited but suggestive evidence that high-to-moderate consumption of fish and } n-3 \text { LC-PUFA } \\
\text { as part of a good diet is associated with reduced BC risk }\end{array}$ \\
\hline CRC & $\begin{array}{l}\text { Fish intake probably decreases CRC risk, and the limited data suggest a possible causal relationship } \\
\text { between } n-3 \text { LC-PUFA intake and CRC reduction }\end{array}$ \\
\hline PC & The evidence of a protective effect of $n-3$ LC-PUFA on PC is limited \\
\hline \multicolumn{2}{|r|}{ ( } \\
\hline CHD events & Convincing evidence of decreased risk \\
\hline Fatal CHD & Probable evidence of decreased risk \\
\hline \multicolumn{2}{|l|}{ Central nervous system functioning } \\
\hline Age-related maculopathy & The strength of the evidence is regarded as possible \\
\hline $\begin{array}{l}\text { Alzheimer's disease, Huntington's disease } \\
\text { and schizophrenia }\end{array}$ & The strength of the evidence is regarded as insufficient \\
\hline Cognitive decline & The strength of the evidence is regarded as possible \\
\hline Depression and bipolar disorder & $\begin{array}{l}\text { The strength of the evidence is regarded as probable for relief of depression and possible for bipolar } \\
\text { disorder }\end{array}$ \\
\hline Inflammatory bowel disease & $\begin{array}{l}\text { A possible benefit (with adequate dose) in Crohn's disease, but there is insufficient evidence of benefit } \\
\text { in ulcerative colitis }\end{array}$ \\
\hline Rheumatoid arthritis & There is convincing evidence of a benefit with an adequate dose \\
\hline
\end{tabular}

$\mathrm{BC}$, breast cancer; $\mathrm{CHD}$, coronary heart disease; $\mathrm{CRC}$, colorectal cancer; $\mathrm{PC}$, prostate cancer. 
of DHA and EPA are mediated by modulation of membrane biophysical properties but also by effects on cell growth, differentiation and functional maturation, and by modulating gene expression during development and at all subsequent stages of human life ${ }^{(2,39)}$. Additionally, fish consumption and hence $n$-3 LC-PUFA has been associated with a reduced risk for a number of chronic diseases (Table 1).

\section{Neurodevelopment in pregnancy and lactation}

n-3 LC-PUFA supplementation during pregnancy has been reported to moderately increase duration of gestation and birth weight ${ }^{(12)}$. Most of the studies found significant differences in some visual or cognitive tests in the offspring or, at least, positive associations between DHA status in the neonate and pregnant mother ${ }^{(33)}$ and neurodevelopmental outcomes $^{(11)}$. Although some inflammatory and vascular homeostasis biomarkers change during pregnancy, they are not affected by the increased intake of farmed salmon ${ }^{(40)}$. In addition, consumption of two portions of salmon per week enhances the antioxidant defence system in pregnant women. Furthermore, the effects of $n$ - 3 LC-PUFA in reducing allergic biomarkers in children seem very promising ${ }^{(41,42)}$.

The effects of $n$-3 LC-PUFA supplementation in pregnant and lactating women and infants during postnatal life on neurodevelopment of children, namely the visual acuity, psychomotor development, mental performance and growth, have been evaluated ${ }^{(11)}$. Some of these studies have reported beneficial effects of DHA supplementation during pregnancy and/or lactation especially on visual acuity outcomes and some on long-term neurodevelopment, but only a few showed positive effects on growth. In particular, some beneficial effects of perinatal DHA supply on later neurological development have been established. In a European multicentre study, neurological development was assessed in children at the age of 4 and 5.5 years after $n$ - 3 LC-PUFA supplementation using maternal supplementation with fish oil and the results suggested that higher DHA levels in cord blood may be related to a better neurological outcome at 5.5 years of age ${ }^{(10)}$.

Some studies also evidenced that most children with inborn errors are deficient in $n$ - 3 LC-PUFA and demonstrated that supplementation might improve their neural function or prevent the progression of neurological impairment although further investigations are needed on this issue ${ }^{(43)}$.

\section{Dementia and age related cognitive impairment}

Observational epidemiological and case-control studies largely support a protective role of fish and other sources of $n$-3 LC-PUFA consumption on cognitive function with advancing age, albeit with important unexplained heterogeneity in findings ${ }^{(44)}$. Indeed, there is not enough scientific evidence to support the routine use of $n-3$ LC-PUFA supplements for the prevention, or amelioration, of cognitive decline in later life.

\section{Cardiovascular and other inflammatory diseases}

Dietary n-3 LC-PUFA are associated with plasma biomarker, reflecting lower levels of inflammation and endothelial activation in CVD and other chronic and acute diseases, including chronic renal disease, sepsis and acute pancreatitis ${ }^{(45)}$. In fact, EPA gives rise to eicosanoid mediators that are less inflammatory than those produced from arachidonic acid and both EPA and DHA give rise to lipoxins, resolvins, protectins and other mediators that are anti-inflammatory and inflammation resolving ${ }^{(46)}$.

$n-3$ LC-PUFA are effective in preventing cardiovascular events, especially in persons with high cardiovascular risk. The accumulated evidence indicates that marine $n-3$ LC-PUFA, when administered as food or in supplements for at least 6 months, reduces cardiovascular events by $10 \%$, cardiac death by $9 \%$ and coronary events by $18 \%$, while showing a trend for a lower total mortality. These results are based on the evaluation of studies that included mainly persons with high cardiovascular risk and on studies that are highly heterogenic in the dose administered, although there is no evidence of dose-dependent protection ${ }^{(8,47)}$.

High doses of $n$-3 LC-PUFA ( $>3 \mathrm{~g} / \mathrm{d})$ produce a small but significant decrease in blood pressure, especially systolic blood pressure, an important risk factor for cardiac and brain events, in older and hypertensive subjects ${ }^{(48)}$. In addition, the well-known hypotriglyceridaemic effect of $n-3$ LC-PUFA may produce further benefits by reducing the percentage of pro-atherogenic small dense LDL particles and also perhaps by ameliorating the inflammatory process associated with metabolic syndrome, which in turn is associated with diabetes mellitus and $\mathrm{CVD}^{(9)}$. However, based on all available evidence from prospective studies, neither EPA or DHA nor fish/seafood intake have significant associations with the risk of diabetes mellitus overall ${ }^{(49)}$.

Marine $n-3$ PUFA have been shown to have a fairly consistent, but modest, benefit of lowering inflammatory symptoms in rheumatoid arthritis, namely joint swelling and pain, duration of morning stiffness, global assessments of pain and disease activity, and use of non-steroidal anti-inflammatory drugs $^{(42)}$. However, available data do not allow supporting the use of $n$-3 LC-PUFA supplementation for the treatment of both active and inactive inflammatory bowel disease ${ }^{(50)}$.

\section{Cancer}

Observational studies on colorectal, prostate and breast cancers only provide limited evidence suggesting a possible role of $n$-3 LC-PUFA in cancer prevention. Knowing the anti-inflammatory activity of these fatty acids, they could play a role as adjuvant in view of the latest randomised controlled trials on lung cancers even if randomised controlled trials on other cancers still need to be undertaken ${ }^{(47,51)}$.

\section{Health risks of fish consumption}

Marine toxins and infectious agents including parasites (nematodes, cestodes and trematodes) and bacteria have been found in seafood products. For example, bivalve molluscs feed by 
filtering large volumes of seawater. During this process, they can accumulate and concentrate pathogenic micro-organisms. The illnesses caused by these agents range from gastrointestinal diseases to severe poisonings (paralytic, amnesic, neurotoxic and diarrhoeic syndromes). Allergens have also been found in seafood products and are usually associated with allergy processes in sensitive subjects.

However, the most concerning problem from a public health point of view is the exposure to low doses of chemical pollutant mixtures (heavy metals and organic compounds such as organochlorine pesticides, polycyclic aromatic hydrocarbons, PCB, dioxins and dibenzofurans) among populations in non-occupational settings, especially women of reproductive age, pregnant or nursing women; breast-fed infants; and young children living in industrial areas. They are exposed by inhaling pollutants from industrial emissions and also by eating and drinking polluted food (including seafood) and water ${ }^{(52,53)}$. Food Safety and Nutrition Agencies have raised public concern as it claimed that some pollutants (e.g. methylmercury) in certain fish species make them unsuitable for consumption by children and pregnant women, so that it is important to provide information in order to achieve a better risk assessment from seafood consumption. For example, European regulations limit the amount and type of certain contaminants that can appear in foodstuffs ${ }^{(54)}$.

More than 1000 chemical substances are known to have neurotoxic effects in experimental animals. Of these, $\mathrm{Pb}$, methylmercury and As are three relevant substances that have been shown to cause neurodevelopmental disorders in humans and subclinical brain dysfunction ${ }^{(52)}$. A number of epidemiological studies on neurobehavioral development in children have been conducted in populations consuming seafood products ${ }^{(55-57)}$ and there is convincing evidence of adverse neurological/neurodevelopmental outcomes in infants and young children associated with methylmercury exposure during fetal development due to maternal fish consumption during pregnancy ${ }^{(6,58)}$. Other important conclusions from FAO and WHO Expert Committee were as follows: (1) the absence of probable or convincing evidence of risk of CHD associated with methylmercury; (2) when comparing the benefits of $n$-3 LC-PUFA with the risks of methylmercury among women of childbearing age, maternal fish consumption lowers the risk of suboptimal neurodevelopment in their offspring compared with the offspring of women not eating fish in most circumstances evaluated.

Also several epidemiological studies provide limited evidence of an association between methylmercury body burden, primarily from fish consumption and CVD ${ }^{(59,60)}$.

Table 2. Estimated amounts of toxic elements ingested by fish in Andalusia, Spain and their respective provisional tolerable weekly intake percentages

\begin{tabular}{lccc}
\hline Metal & Weekly intake $(\mu \mathrm{g} /$ week $)$ & PTWI $(\mu \mathrm{g} /$ week $)$ & PTWI $(\%)$ \\
\hline $\mathrm{Hg}$ & 63.63 & 96 & 66.281 \\
$\mathrm{Cd}$ & 17.57 & 150 & 11.713 \\
$\mathrm{~Pb}$ & 75.95 & 1500 & 5.063 \\
$\mathrm{Sn}$ & 15.40 & 840000 & 0.002 \\
\hline
\end{tabular}

PTWI, provisional tolerable weekly intake.
More recently, our research team ${ }^{(17)}$ has published the levels of $\mathrm{Hg}, \mathrm{Cd}, \mathrm{Pb}, \mathrm{Sn}$ and $\mathrm{As}$ in fresh, canned and frozen fish and shellfish products from a total of 485 samples of the forty-three most frequently consumed species in Andalusia (Southern Spain). High $\mathrm{Hg}$ concentrations were found in some predatory species (blue shark, cat shark, swordfish and tuna), although they were below the regulatory maximum levels (Table 2 and Fig. 1). In the case of Cd, bivalve molluscs such as canned clams and mussels presented higher concentrations than fish, but almost none of the samples analysed exceeded the maximum levels regulated. $\mathrm{Pb}$ concentrations were almost negligible with the exception of frozen common sole, which showed median levels above the legal limit. Sn levels in canned products were far below the maximum regulatory limit, indicating that no significant Sn was transferred from the can. As concentrations were higher in crustaceans such as fresh and frozen shrimps. Storelli et al. ${ }^{(61)}$ found similar $\mathrm{Hg}$ levels in fresh tuna $(0.530 \mathrm{mg} / \mathrm{kg} \mathrm{ww})$ and swordfish $(0 \cdot 800 \mathrm{mg} / \mathrm{kg} \mathrm{ww})$. However, in our samples analysed, Cd concentrations were rather low, which is in contrast to Storelli et al. ${ }^{(61)}$ who found remarkable Cd levels in cuttlefish and swordfish $(0.85$ and $0.25 \mathrm{mg} / \mathrm{kg} \mathrm{ww}$, respectively) caught in Italy. The risk assessment performed indicated that fish and shellfish products were safe for the average consumer, although a potential risk cannot be dismissed for regular or excessive consumers of particular fish species, such as tuna, swordfish, blue shark and cat shark (for $\mathrm{Hg}$ ) and common sole (for $\mathrm{Pb}$ ).

We have also published ${ }^{(16)}$ the levels of four essential elements ( $\mathrm{Cu}, \mathrm{Mn}$, Se and $\mathrm{Zn}$ ) in fish and shellfish products mentioned earlier, including the risk and nutritional assessment and $\mathrm{Hg}$ :Se ratios as well as Se health benefit value. Concerning Se, probably the most important of them, two fresh predatory fish species (tuna and swordfish) presented the most remarkable concentrations of this element. All the species analysed showed beneficial $\mathrm{Hg}$ :Se ratios and $\mathrm{Se}$ health benefit values, except for the shark species (blue shark and cat shark) and gilt-head bream because of their high $\mathrm{Hg}$ levels and low Se content, respectively. Nevertheless, the biomagnification usually observed in hazardous metals such as $\mathrm{Hg}$ would not occur for the essential elements measured in predatory species. The contribution of seafood products to the recommended daily allowances and adequate intakes of these mineral elements ranges from $2.5 \%(\mathrm{Mn})$ to $25.4 \%$ (Se). The species more advisable according to Se health benefit values were sardine and anchovy.

Moreover, PCDD and PCDF, PCB including dioxin-like PCB and non-dioxin-like PCB, organochlorine pesticides, and polybrominated diphenyl ethers are lipophillic organic compounds whose origin comes from many different sources. PCDD/PCDF and PCB are ubiquitous and persistent environmental pollutants with a well-known potential toxicity ${ }^{(62,63)}$. Dioxin and PCB levels in fish are usually low and potential carcinogenic and other effects are outweighed by potential benefits of fish intake and should have little impact on choices or consumption of seafood ${ }^{(14)}$. Although dioxins can cause a variety of adverse health effects, including cancer, effects on the immune system, reproductive system, nervous system 
(a)

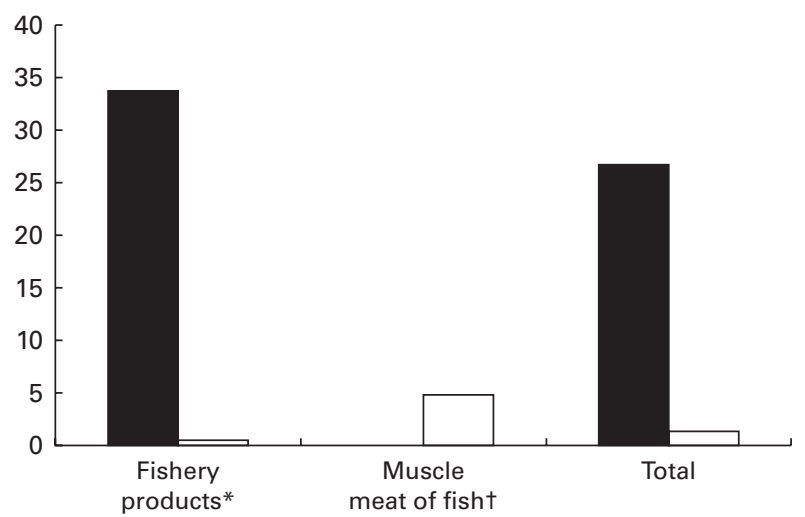

(c)

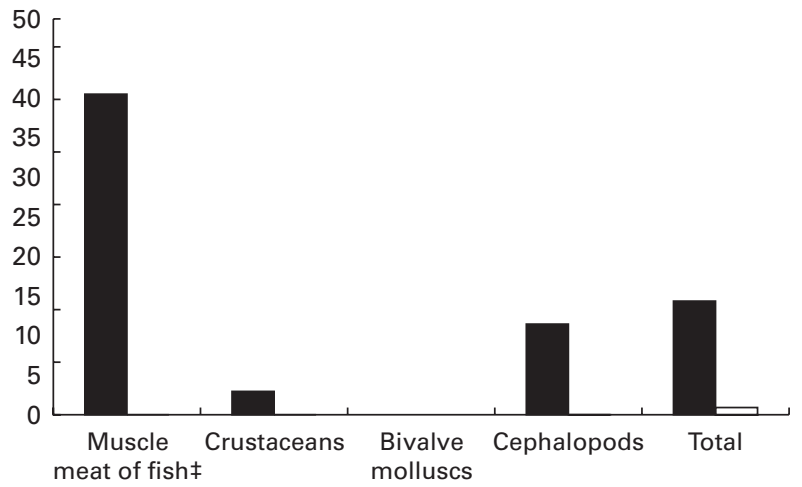

(b)

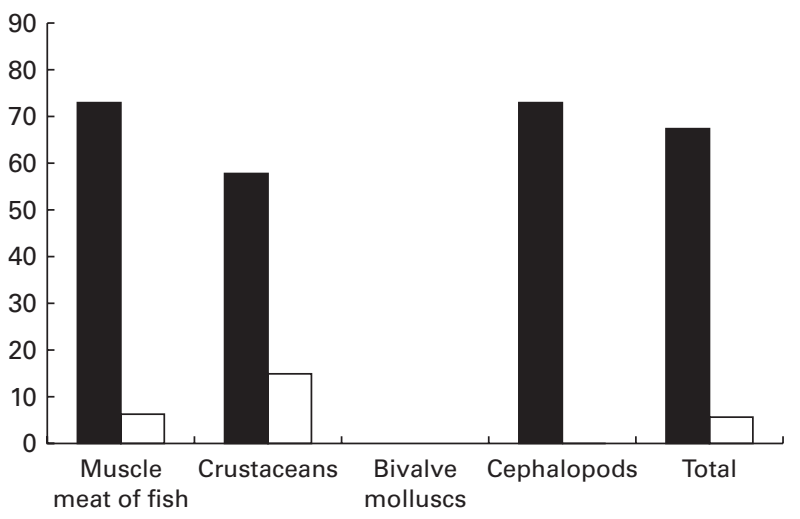

(d)

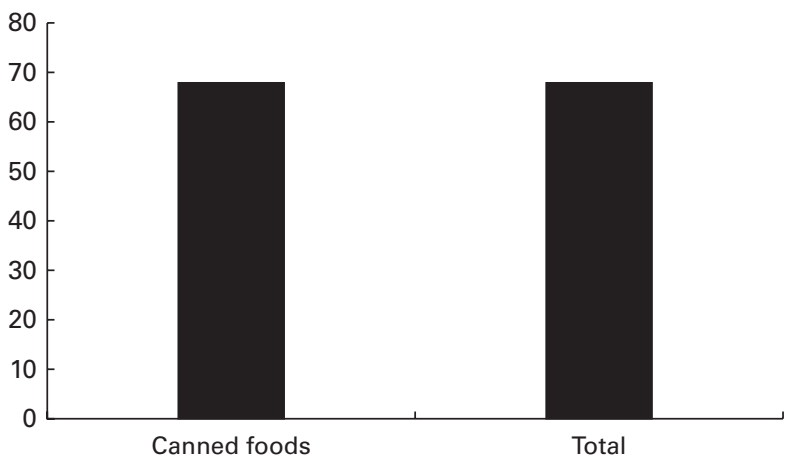

Fig. 1. Comparison between metal levels ((a) mercury, (b) lead, (c) cadmium and (d) tin) found in fish and shellfish Spanish samples analysed and the legal categories for each metal according to the European Commission (Regulation EC no. 1881/2006 amended by EC no. 629/2008 and EC no. 420/2011). ${ }^{*}$ Includes muscle meat fish excluding 3.3.2 category. † Muscle meat of fish for category 3.3.2. $\ddagger$ Muscle meat of fish (all categories). $\mathbf{\square}$, Number of samples and percentage under limit of detection. $\square$, Number of samples and percentage over the maximum legal limit.

and endocrine system, it has been concluded that at levels of maternal exposure to dioxins (from fish and other dietary sources) that do not exceed the provisional tolerable monthly intake of $70 \mathrm{pg} / \mathrm{kg}$ body weight established by Joint FAO/ WHO Expert Committee on Food Additives (JECFA) (for PCDD, PCDF and coplanar PCB), neurodevelopmental risk for the fetus is negligible. At levels of maternal exposure to dioxins (from fish and other dietary sources) that exceed the provisional tolerable monthly intake, neurodevelopmental risk for the fetus may no longer be negligible. Finally, they observed that there was insufficient evidence for adverse health effects (e.g. endocrine disruption, immunological and neurodevelopmental effects, and cancer) associated with exposure to dioxins from fish consumption ${ }^{(6)}$. Only a specific fish preparation (Cantonese salted fermented fish) has been identified as being convincingly associated with nasopharyngeal cancer ${ }^{(64)}$. For example, in France, PCB and dioxins were far below the regulatory thresholds in oysters $(<0.6 \mathrm{pg} / \mathrm{g})$, mussels $(<0.6 \mathrm{pg} / \mathrm{g})$ and king scallops $(<0.4 \mathrm{pg} / \mathrm{g})$, despite of species that filter large volumes of water to extract their food and thus could be excellent bioaccumulators of marine environmental pollutants ${ }^{(65)}$. However, it is always necessary to consider the exception of certain products from specific regions located around known heavypoint source. Generally, European consumers have higher exposure levels of PCDD/PCDF and dioxin-like-PCB, while American and Asians have relatively higher exposure levels of organochlorine pesticides and PCB. By contrast, all global populations are found to have lower exposure levels of polybrominated diphenyl ethers, which may be attributed to its relatively shorter history of use compared with PCB and organochlorine pesticides ${ }^{(63)}$.

Total dietary intake of PCDD/PCDF for the general population of Tarragona County was estimated to be $27 \cdot 81 \mathrm{pg}$ WHO-toxic equivalents/d established by the WHO in 1998, value notably lower than that found in the 2002 study (63.80 pg WHO-toxic equivalents/d). Fish and seafood were the most important contributors (28\%) to this intake, although it seems quite evident that in recent years the dietary intake of PCDD/PCDF has considerably diminished as a direct consequence of the reduction in the atmospheric emissions of these environmental pollutants ${ }^{(66)}$

Guéguen et al. ${ }^{(65)}$ have also published the benzo(a)pyrene concentration in shellfish (marketed mussels and farmed shellfish) but does not exceed the regulatory European threshold. Martorell et al. ${ }^{(15)}$ have shown an important decreasing trend in the dietary exposure to polycyclic aromatic hydrocarbons (PAH) for the population living in Catalonia and they found that fish and seafood products contributed 
Table 3. Health benefits $v$. risks derived from regular fish consumption*

\begin{tabular}{|c|c|}
\hline Benefits & Major outcomes \\
\hline $\begin{array}{l}\text { High biological value and digestibility proteins } \\
\text { especially rich in Leu, Val, Thr, Lys and Trp }\end{array}$ & $\begin{array}{l}\text { Adequate growth and development } \\
\text { Positive for human gut health }\end{array}$ \\
\hline $\begin{array}{l}\text { High amount of non-protein } \mathrm{N} \text { compounds } \\
\text { (free amino acids, peptides, nucleotides, etc.) }\end{array}$ & $\begin{array}{l}\text { Taurine, a semi-essential amino acid, has been associated with } \\
\text { visual acuity, brain development and positive health effects of the } \\
\text { cardiovascular system. Limited evidence of positive effect on } \\
\text { metabolic syndrome form animal studies } \\
\text { Dietary nucleotides have been reported to positively modulate the } \\
\text { immune system in infancy and adults }\end{array}$ \\
\hline $\begin{array}{l}\text { High amounts of long-chain } n-3 \text { PUFA, namely } \\
\text { EPA and DHA }\end{array}$ & $\begin{array}{l}\text { Improve early-life visual and cognitive development } \\
\text { Positive effects on prevention of hypertension, metabolic syndrome, } \\
\text { and CVD and stroke } \\
\text { Reduction of inflammatory biomarkers and protection for rheumatoid } \\
\text { arthritis, inflammatory intestinal diseases and colorectal cancer } \\
\text { Possible protection of neurodegenerative diseases in the elderly }\end{array}$ \\
\hline $\begin{array}{l}\text { Marine fish species and molluscs contain a } \\
\text { number of trace elements in concentrations } \\
\text { favourable for human nutrition (one of the } \\
\text { few natural sources of Se and I and good } \\
\text { sources of } \mathrm{Fe}, \mathrm{Cu}, \mathrm{Zn} \text { and } \mathrm{F} \text { ) }\end{array}$ & $\begin{array}{l}\text { Key roles in nutrition to prevent numerous diseases. Se has a } \\
\text { probable protective effect for metabolic syndrome and atopy }\end{array}$ \\
\hline $\begin{array}{l}\text { Valuable source of vitamins, } A, D, B_{1}, B_{2} \\
\text { niacin, } B_{6} \text { and } B_{12}\end{array}$ & $\begin{array}{l}\text { Key functions in growth, development, metabolism and control } \\
\text { of gene expression and prevention of numerous diseases. } \\
\text { Vitamin } \mathrm{B}_{12} \text { has a role in reducing homocysteine levels and } \\
\text { protection of vascular health and possible effect in colorectal } \\
\text { cancer prevention. There is evidence of positive effects on } \\
\text { cognitive development and dementia }\end{array}$ \\
\hline \multicolumn{2}{|l|}{ Risks } \\
\hline $\begin{array}{l}\text { Parasites (nematodes, cestodes and } \\
\text { trematodes) }\end{array}$ & Parasitic infection \\
\hline Pathogenic bacteria & Gastrointestinal diseases \\
\hline Marine toxins (from harmful algal bloom) & Paralytic, amnesic, ciguatera, neurotoxic and diarrhoeic poisonings \\
\hline Biogenic amines (histamine) & Scombroid poisoning \\
\hline Fish allergens & Allergy in sensitive subjects \\
\hline $\begin{array}{l}\text { Methylmercury accumulation in predatory } \\
\text { species }\end{array}$ & Impaired neurological development and teratogenesis \\
\hline Cd accumulation in molluscs & Renal disease \\
\hline $\begin{array}{l}\text { Organic compounds (OCP, PAH, PCB, dioxins } \\
\text { and dibenzofurans) }\end{array}$ & $\begin{array}{l}\text { Endocrine disruption, immunological and neurodevelopmental } \\
\text { effects, and cancer }\end{array}$ \\
\hline
\end{tabular}

with $3.6 \%$ to the total PAH food intake in contrast to meat and meat products $(49 \cdot 2 \%)$.

Several international projects have been developed to approach risk-benefit assessment from fish consumption. Among them, Benefit-Risk Analysis of Foods ${ }^{(67)}$, Benefit-Risk Assessment for Food and Quality of Life-Integrated Benefit and Risk Analysis should be highlighted ${ }^{(6)}$. Other specific tools have been performed for risk-benefit assessment such as European Food Safety Agency (EFSA) guidelines ${ }^{(68)}$, disabilityadjusted life-year ${ }^{(69)}$, quality-adjusted life-year ${ }^{(70)}$, fish riskbenefit assessment by the Institute of Medicine in the USA and quantitative risk-benefit assessment of fish consumption by the USFDA ${ }^{(71)}$. In general, the aim has been to establish diagrams for exposure and dose-response modelling and to compare/ estimate following a matrix combining the positive effects or benefits from fish intake (e.g. from $n$-3 LC-PUFA) and negative effects or risks (e.g. from environmental pollutant) on the common health end points (e.g. child intelligence quotient or mortality), depending on the number of servings per week. Thereby, these matrices allow estimating changes in these end points resulting from the child's mother having consumed fish with different contaminants and essential elements including EPA and DHA contents at different servings per week.

Finally, Table 3 summarises the main health outcomes associated with seafood product consumption including the benefits and risks ${ }^{(3,21-27)}$.

\section{Conclusions}

Fish consumption and hence $n-3$ LC-PUFA have key roles in neurodevelopment and in the prevention of chronic diseases, particularly cardiovascular pathologies. Consumer vigilance is necessary among regular fish consumers, and especially for those residing in fishing areas, for pregnant and breastfeeding women, and for very young children. In addition, general recommendations about fish consumption should be done taking into account the data concerning levels of environmental pollutants in the most consumed marine species in each specific region or country. According to the FAO/WHO Expert Committee, the fish species, the frequency of consumption and the meal size are essential issues for an adequate balance of the health benefits and risks of a 
regular fish intake. In conclusion, for major health outcomes among adults, the vast majority of epidemiological studies have proven that the benefits of fish intake exceed the potential risks excepting a few selected species in sensitive populations. However, in order to minimise the risk in these specific populations, it would be necessary to develop and improve existing databases on specific contaminants in seafood products. Therefore, fish consumption is beneficial to health although seafood products must be controlled, especially on environmental pollutants.

\section{Acknowledgements}

This work was financially supported by the Redes Temáticas de Investigación Cooperativa (A. G., Red no. RD08/0072/ 0028 and SAMID RD12/0026/0015) and the Instituto de Salud Carlos III-Fondo de Investigación Sanitaria (F. G., Project no. PI10/00527), Ministry of Health, Spain.

The authors' contributions are as follows: A. G. and F. G. have contributed equally to the conception, design and discussion of the revision article and to the writing of the manuscript; A. G. (a nutritionist and biochemistry scientist) has contributed especially to the benefits section; F. G. (a toxicologist scientist) has mainly carried out the risk section of seafood product consumption.

None of the authors has no conflict of interest.

\section{References}

1. Pieniak Z, Verbeke W \& Scholderer J (2010) Health-related beliefs and consumer knowledge as determinants of fish consumption. J Hum Nutr Diet 23, 480-488.

2. Gil A, Serra-Majem L, Calder PC, et al. (2012) Systematic reviews of the role of omega-3 fatty acids in the prevention and treatment of disease. Br J Nutr 107, Suppl. 2, S1-S2.

3. Oehlenschläger J (2012) Seafood: nutritional benefits and risk aspects. Int J Vitam Nutr Res 82, 168-176.

4. Swanson D, Block R \& Mousa SA (2012) Omega-3 fatty acids EPA and DHA: health benefits throughout life. Adv Nutr 3, 1-7.

5. Tur JA, Bibiloni MM, Sureda A, et al. (2012) Dietary sources of omega 3 fatty acids: public health risks and benefits. $\mathrm{BrJ}$ Nutr 107, Suppl. 2, S23-S52.

6. Food and Agriculture Organization of the United Nations (FAO) and World Health Organization (WHO) (2010) Joint FAO/WHO Expert Consultation on the Risks and Benefits of Fish Consumption FAO Fisheries and Aquaculture Report no. 978. Roma/Geneva: FAO/WHO.

7. Mozaffarian D \& Wu JH (2011) Omega-3 fatty acids and cardiovascular disease: effects on risk factors, molecular pathways, and clinical events. J Am Coll Cardiol 58, 2047-2067.

8. Delgado-Lista J, Perez-Martinez $\mathrm{P}$, Lopez-Miranda J, et al. (2012) Long chain omega-3 fatty acids and cardiovascular disease: a systematic review. BrJ Nutr 107, Suppl. 2, S201-S213.

9. Lopez-Huertas E (2012) The effect of EPA and DHA on metabolic syndrome patients: a systematic review of randomised controlled trials. Br J Nutr 107, Suppl. 2, S185-S194.

10. Escolano-Margarit MV, Ramos R, Beyer J, et al. (2011) Prenatal DHA status and neurological outcome in children at age $5 \cdot 5$ years are positively associated. J Nutr 141, 1216-1223.
11. Campoy C, Escolano-Margarit MV, Anjos T, et al. (2012) Omega 3 fatty acids on child growth, visual acuity and neurodevelopment. Br J Nutr 107, Suppl. 2, S85-S106.

12. Larqué E, Gil-Sánchez A, Prieto-Sánchez MT, et al. (2012) Omega 3 fatty acids, gestation and pregnancy outcomes. Br J Nutr 107, Suppl. 2, S77-S84.

13. Domingo JL (2007) Omega-3 fatty acids and the benefits of fish consumption: is all that glitters gold? Environ Int 33, 993-998.

14. Mozaffarian D \& Rimm EB (2006) Fish intake, contaminants, and human health: evaluating the risks and the benefits. JAMA 296, 1885-1899.

15. Martorell I, Perelló G, Martí-Cid R, et al. (2011) Human exposure to arsenic, cadmium, mercury, and lead from foods in Catalonia, Spain: temporal trend. Biol Trace Elem Res 14, 309-322.

16. Olmedo P, Hernández AF, Pla A, et al. (2013) Determination of essential elements (copper, manganese, selenium and zinc) in fish and shellfish samples. Risk and nutritional assessment and mercury-selenium balance. Food Chem Toxicol 62, 299-307.

17. Olmedo P, Pla A, Hernández AF, et al. (2013) Determination of toxic elements (mercury, cadmium, lead, tin and arsenic) in fish and shellfish samples. Risk assessment for the consumers. Environ Int 59, 63-72.

18. Bushkin-Bedient S \& Carpenter DO (2010) Benefits versus risks associated with consumption of fish and other seafood. Rev Environ Health 25, 161-191.

19. Ros G, Martinez-Graciá C \& Santaella-Pascual M (2010) Pescados y mariscos (Fish and seafoods). In Tratado de Nutrición (Treatise of Nutrition), vol. II, pp. 55-73 [A Gil, editor]. Madrid: Editorial Medica Panamericana.

20. Sirot V, Dumas C, Leblanc JC, et al. (2011) Food and nutrient intakes of French frequent seafood consumers with regard to fish consumption recommendations: results from the CALIPSO study. Br J Nutr 105, 1369-1380.

21. Lund EK (2013) Health benefits of seafood; is it just the fatty acids? Food Chem 140, 413-420.

22. Zampelas A, Panagiotakos DB, Pitsavos C, et al. (2005) Fish consumption among healthy adults is associated with decreased levels of inflammatory markers related to cardiovascular disease: The ATTICA study. J Am Coll Cardiol 46, 120-124.

23. Panagiotakos DB, Zeimbekis A, Boutziouka V, et al. (2007) Long-term fish intake is associated with better lipid profile, arterial blood pressure, and blood glucose levels in elderly people from Mediterranean islands (MEDIS epidemiological study). Med Sci Monit 13, CR307-312.

24. Bouzan C, Cohen JT, Connor WE, et al. (2005) A quantitative analysis of fish consumption and stroke risk. Am J Prev Med 29, 347-352.

25. He K, Song Y, Daviglus ML, et al. (2004) Fish consumption and incidence of stroke: a meta-analysis of cohort studies. Stroke 35, 1538-1542.

26. Manna P, Das J \& Sil PC (2013) Role of sulfur containing amino acids as an adjuvant therapy in the prevention of diabetes and its associated complications. Curr Diabetes $\operatorname{Rev}$ 9, 237-248.

27. Ryan-Harshman $M$ \& Aldoori W (2008) Vitamin $B_{12}$ and health. Can Fam Physician 54, 536-541.

28. Chasapis CT, Loutsidou AC, Spiliopoulou CA, et al. (2012) Zinc and human health: an update. Arch Toxicol 86, 521-534.

29. Stern BR (2010) Essentiality and toxicity in copper health risk assessment: overview, update and regulatory considerations. $J$ Toxicol Environ Health A 73, 114-127. 
30. Flores-Mateo G, Navas-Acien A, Pastor-Barriuso $\mathrm{R}$, et al. (2006) Selenium and coronary heart disease: a meta-analysis Am J Clin Nutr 84, 762-773.

31. Greenwald P, Anderson D, Nelson SA, et al. (2007) Clinical trials of vitamin and mineral supplements for cancer prevention. Am J Clin Nutr 85, 314-317.

32. Parra D, Bandarra NM, Kiely M, et al. (2007) Impact of fish intake on oxidative stress when included into a moderate energy-restricted program to treat obesity. Eur J Nutr 46, $460-467$.

33. García-Rodríguez CE, Mesa MD, Olza J, et al. (2012) Does consumption of two portions of salmon per week enhance the antioxidant defense system in pregnant women? Antioxid Redox Signal 16, 1401-1406.

34. Bates CJ, Prentice A, Birch MC, et al. (2006) Blood indices of selenium and mercury, and their correlations with fish intake, in young people living in Britain. BrJ Nutr 96, 523-531.

35. Park K \& Mozaffarian D (2010) Omega-3 fatty acids, mercury, and selenium in fish and the risk of cardiovascular diseases. Curr Atheroscler Rep 12, 414-422.

36. Burger J \& Gochfeld M (2011) Mercury and selenium levels in 19 species of saltwater fish from New Jersey as a function of species, size, and season. Sci Total Environ 409, 1418-1429.

37. Geelen A, Schouten JM, Kamphuis C, et al. (2007) Fish consumption, $n-3$ fatty acids, and colorectal cancer: a meta-analysis of prospective cohort studies. Am J Epidemiol 166, 1116-1125.

38. Linseisen J, Rohrmann S, Bueno-de-Mesquita B, et al. (2011) Consumption of meat and fish and risk of lung cancer: results from the European Prospective Investigation into Cancer and Nutrition. Cancer Causes Control 22, 909-918.

39. Corella D \& Ordovás JM (2012) Interactions between dietary $n-3$ fatty acids and genetic variants and risk of disease. Br J Nutr 107, Suppl. 2, S271-S283.

40. García-Rodríguez CE, Olza J, Aguilera CM, et al. (2012) Plasma inflammatory and vascular homeostasis biomarkers increase during human pregnancy but are not affected by oily fish intake. J Nutr 142, 1191-1196.

41. Kremmyda LS, Vlachava M \& Noakes PS (2011) Atopy risk in infants and children in relation to early exposure to fish, oily fish, or long-chain omega-3 fatty acids: a systematic review. Clin Rev Allergy Immunol 41, 36-66.

42. Miles EA \& Calder PC (2012) Influence of marine $n$-3 polyunsaturated fatty acids on immune function and a systematic review of their effects on clinical outcomes in rheumatoid arthritis. Br J Nutr 107, Suppl. 2, S171-S184.

43. Gil-Campos M \& Sanjurjo Crespo P (2012) Omega 3 fatty acids and inborn errors of metabolism. Br J Nutr 107, Suppl. 2, S129-S136.

44. Dangour AD, Andreeva VA, Sydenham E, et al. (2012) Omega 3 fatty acids and cognitive health in older people. Br J Nutr 107, Suppl. 2, S152-S158

45. Rangel-Huerta OD, Aguilera CM, Mesa MD, et al. (2012) Omega-3 long-chain polyunsaturated fatty acids supplementation on inflammatory biomakers: a systematic review of randomised clinical trials. Br J Nutr 107, Suppl. 2, S159-S170

46. Serhan CN, Krishnamoorthy S, Recchiuti A, et al. (2011) Novel anti-inflammatory - pro-resolving mediators and their receptors. Curr Top Med Chem 11, 629-647.

47. Food and Agriculture Organization of the United Nations (FAO) (2010) Fats and Fatty Acids in Human Nutrition. Report of an Expert Consultation, FAO Food and Nutrition Paper no. 91. Roma: FAO.

48. Cabo J, Alonso R \& Mata P (2012) Omega-3 fatty acids and blood pressure. Br J Nutr 107, Suppl. 2, S195-S200.
49. Wu JH, Micha R, Imamura F, et al. (2012) Omega-3 fatty acids and incident type 2 diabetes: a systematic review and meta-analysis. Br J Nutr 107, Suppl. 2, S214-S227.

50. Cabré E, Mañosa M \& Gassull MA (2012) Omega-3 fatty acids and inflammatory bowel diseases - a systematic review. BrJ Nutr 107, Suppl. 2, S240-S252.

51. Gerber M (2012) Omega-3 fatty acids and cancers: a systematic update review of epidemiological studies. Br J Nutr 107, Suppl. 2, S228-S239.

52. Rodríguez-Barranco M, Lacasaña M, Aguilar-Garduño C, et al. (2013) Association of arsenic, cadmium and manganese exposure with neurodevelopment and behavioural disorders in children: a systematic review and meta-analysis. Sci Total Environ 455, 562-577.

53. Hernández AF, Gil F \& Tsatsakis AM (2014) Biomarkers of chemical mixtures toxicity. In Biomarkers in Toxicology, 1st ed., pp. 655-670 [R Gupta, editor]. Oxford: Academic Press.

54. EC (2011) Commission Regulation no. 420/2011 of 29 April 2011 Amending Regulation (EC) no. 1881/2006 Setting Maximum Levels for Certain Contaminants in Foodstuffs (Text with EEA relevance). Off J Eur Union L111, 3-6.

55. Grandjean P, Weihe P, White RF, et al. (1997) Cognitive deficit in 7-year-old children with prenatal exposure to methylmercury. Neurotoxicol Teratol 19, 417-428.

56. Myers GJ, Davidson PW, Cox C, et al. (2003) Prenatal methylmercury exposure from ocean fish consumption in the Seychelles Child Development Study. Lancet 361, $1686-1692$

57. Davidson PW, Strain JJ, Myers GJ, et al. (2008) Neurodevelopmental effects of maternal nutritional status and exposure to methylmercury from eating fish during pregnancy. Neurotoxicol 29, 767-775.

58. Axelrad DA, Bellinger DC, Ryan LM, et al. (2007) Doseresponse relationship of prenatal mercury exposure and IQ: an integrative analysis of epidemiologic data. Environ Health Perspect 115, 609-615.

59. Hallgren CG, Hallmans G, Jansson JH, et al. (2001) Markers of high fish intake are associated with decreased risk of a first myocardial infarction. Br J Nutr 86, 397-404.

60. Yoshizawa K, Rimm EB, Morris JS, et al. (2002) Mercury and the risk of coronary heart disease in men. $N$ Engl J Med $\mathbf{3 4 7}$, $1755-1760$

61. Storelli MM, Normanno G, Barone G, et al. (2012) Toxic metals $(\mathrm{Hg}, \mathrm{Cd}$, and $\mathrm{Pb})$ in fishery products imported into Italy: suitability for human consumption. J Food Prot $\mathbf{7 5}$, 189-194.

62. Domingo JL \& Bocio A (2007) Levels of PCDD/PCDFs and PCBs in edible marine species and human intake: a literature review. Environ Int 33, 397-405.

63. Yu HY, Guo Y \& Zeng EY (2010) Dietary intake of persistent organic pollutants and potential health risks via consumption of global aquatic products. Environ Toxicol Chem 29, $2135-2142$.

64. World Cancer Research Fund, American Institute for Cancer Research (2007) Food, Nutrition, Physical Activity, and the Prevention of Cancer: A Global Perspective, 2nd ed. Washington, DC: American Institute for Cancer Research.

65. Guéguen M, Amiard JC, Arnich N, et al. (2011) Shellfish and residual chemical contaminants: hazards, monitoring, and health risk assessment along French coasts. Rev Environ Contam Toxicol 213, 55-111.

66. Martí-Cid R, Bocio A \& Domingo JL (2008) Dietary exposure to $\mathrm{PCDD} / \mathrm{PCDFs}$ by individuals living near a hazardous 
waste incinerator in Catalonia, Spain: temporal trend. Chemosphere 70, 1588-1595.

67. Hoekstra J, Hart A, Boobis A, et al. (2012) BRAFO tiered approach for benefit-risk assessment of foods. Food Chem Toxicol 50, Suppl. 4, S684-S698.

68. EFSA Scientific Committee (2010) Scientific opinion: guidance on human health risk-benefit assessment of foods. EFSA J 8, 1673. http://www.efsa.europa.eu/de/scdocs/doc/ 1673.pdf (accessed 6 December 2014)

69. Hoekstra J, Verkaik-Kloosterman J, Rompelberg C, et al. (2008) Integrated risk-benefit analyses: method development with folic acid as example. Food Chem Toxicol 46, 893-909.
70. Ponce RA, Bartell SM, Wong EY, et al. (2000) Use of qualityadjusted life year weights with dose-response models for public health decisions: a case study of the risks and benefits of fish consumption. Risk Anal 20, 529-542.

71. USFDA (2009) Report of quantitative risk and benefit assessment of consumption of commercial fish, focusing on fetal neurodevelopment effects (measured by verbal development in children) and on coronary heart disease and stroke in the general population. Draft report. United States Department of Health and Human Services, Food and Drug Administration. http://www.fda.gov/food/food borneillnesscontaminants/metals/ucm088794.htm (accessed 6 December 2014). 